\title{
Reporting of financial conflicts of interest by Canadian clinical practice guideline producers: a descriptive study
}

\author{
Katharine Elder MA, Kimberly A. Turner MSc, Lisa Cosgrove PhD, Joel Lexchin MD, Adrienne Shnier PhD JD, \\ Ainsley Moore MD, Sharon Straus MD, Brett D. Thombs PhD
}

Cite as: CMAJ 2020 June 8;192:E617-25. doi: 10.1503/cmaj.191737

\begin{abstract}
BACKGROUND: The producers of clinical practice guidelines (CPGs) may not disclose industry funding in their CPGs. We reviewed Canadian national CPGs to examine the existence and disclosure of industry-related organizational funding in the CPGs, financial conflicts of interest of committee members and organizational procedures for managing financial conflicts of interest.
\end{abstract}

METHODS: For this descriptive study, we searched the asset map of the Strategy for Patient-Oriented Research Evidence Alliance and the CPG Infobase for CPGs published between Jan. 1, 2016, and Nov. 30,2018 . Eligible guidelines had to have a national focus and either a first-line drug recommendation or a screening recommendation leading to drug treatment. One investigator reviewed all CPG titles to exclude those that were clearly ineligible.
Two reviewers independently reviewed all remaining guidelines and extracted data. We analyzed the data descriptively.

RESULTS: We included 21 CPGs: 3 from government-sponsored organizations, 9 from disease or condition interest groups and 9 from medical professional societies. None of the 3 governmentsponsored organizations reported industry funding, and none of their committee members disclosed financial conflicts of interest. Among the 18 disease or condition interest groups and medical professional societies, 14 (93\%) of the 15 that disclosed funding sources on websites (3 did not disclose) reported organizational funding from industry, but none disclosed this information in the CPGs; 12 (86\%) of the 14 with conflict-of-interest disclosure statements in the CPG (4 did not include disclosures) had at least 1 committee member with a financial conflict (mean proportion of committee members with a conflict 56\%); and for all 8 CPGs with identifiable chairs or cochairs (chairs or cochairs not reported for 10) at least 1 of these people had a financial conflict of interest. None of the guidelines described a plan to manage organizational financial conflicts of interest.

INTERPRETATION: Canadian CPGs are vulnerable to industry influence through funding of producers of guidelines and through the financial conflicts of interest of committee members. The CPG producers that receive industry funding should disclose organizational financial conflicts in the CPGs, should engage independent oversight committees and should restrict voting on recommendations to guideline panelists who have no financial conflicts.

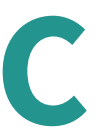

linical practice guidelines (CPGs) support clinical decision-making and health care practice standards and are among the most-cited articles in medical journals. There is recognition of the need to develop CPGs that are free of commercial influences. ${ }^{1-8}$

Industry sponsorship of research and investigators' financial conflicts of interest are associated with reporting favourable results, drawing conclusions that overstate positive effects, and understating or ignoring harms. ${ }^{9-19}$ Physicians who interact with the pharmaceutical industry and its representatives write more prescriptions and prescribe more expensive drugs than those who do not have such interactions. ${ }^{20,21}$ The development of CPGs requires careful assessment of the benefits and harms of care options, which involves interpreting evidence and making valuebased judgments. ${ }^{22-25}$ In this context, there is a risk that the financial conflicts of interest of committee members may influence recommendations. ${ }^{1-7,22-35}$ This risk may be exacerbated if organizations that produce CPGs depend on industry funding to support their activities. ${ }^{2,33-35}$

Recommendations published in 2011 by the US Institute of Medicine (now known as the National Academy of Medicine) emphasized that funders should not have any role in CPG development, 
but they did not specify whether CPG producers should accept industry funding for CPG development, nor did they address the disclosure and management of financial conflicts of interest of the CPG producer. ${ }^{23}$ The principles of the Guidelines International Network (GIN) address the management of financial conflicts of interest of CPG committee members but not the financial conflicts of the organizations that oversee CPG production. ${ }^{22}$

We aimed to determine the proportion of Canadian national CPGs published since 2016 with recommendations related to medications that disclosed industry-related organizational funding, either in the CPGs themselves or at organizational websites; the proportion of guidelines with financial conflicts of interest that were disclosed in the CPGs; the proportion of CPG committee members with financial conflicts of interest; and whether organizational procedures for managing financial conflicts of interest were described in the CPGs.

\section{Methods}

We examined Canadian national CPGs published in 2016 or later. We chose this starting date, 5 years after publication of the Institute of Medicine recommendations, ${ }^{23}$ because these were the first influential recommendations to address management of financial conflicts of interest in CPGs, and we believed that 5 years provided sufficient time for their dissemination and integration into CPGs. We chose a descriptive design that included evaluation of CPGs and of the websites of producer organizations, so that we could compare information on industry associations that was reported in CPGs with external information available elsewhere for most organizations. The initial protocol and a final version with amendments are available on the Open Science Framework (https://osf.io/uz7ew/).

Clinical practice guidelines have been defined as "systematically developed statements to assist practitioner and patient decisions about appropriate health care for specific clinical circumstances." ${ }^{36}$ We classified CPGs as national if they were intended for use across Canada and were not created and intended for use in regional or provincial populations only. We used the Institute of Medicine's definition of conflicts of interest as "a set of circumstances that creates a risk that professional judgment or actions regarding a primary interest will be unduly influenced by a secondary interest." ${ }^{37}$ For the purpose of this study, we limited this definition to financial conflicts of interest.

\section{Identification and selection of eligible CPGs}

One investigator (K.E.) searched for CPGs published between Jan. 1, 2016, and Nov. 30, 2018, using the asset map of the Strategy for Patient-Oriented Research Evidence Alliance ${ }^{38}$ and the CPG Infobase. ${ }^{39}$ The searches were initially conducted on Nov. 30, 2018, with an additional prepublication search on Feb. 9, 2020, to ensure that we did not miss eligible CPGs from the study period that might have subsequently been added to the CPG Infobase. The Strategy for Patient-Oriented Research Evidence Alliance asset map is a database of national, provincial and local Canadian CPGs published between 1996 and April 2018, identified from 12 different sources. ${ }^{38}$ The CPG Infobase is a repository of about 1200 CPGs developed or endorsed by Canadian medical or health organizations. ${ }^{39}$ Inclusion and exclusion criteria are shown in Box 1.
Box 1: Clinical practice guideline inclusion and exclusion criteria

\section{Inclusion criteria}

- Contains 1 or more recommendations on either first-line drug management or whether to provide screening interventions leading to drug treatments (e.g., hepatitis C screening)

- National (intended for use across Canada)

- Published between Jan. 1, 2016, and Nov. 30, 2018

\section{Exclusion criteria}

- Recommendations unrelated to either first-line drug treatments or use of procedures that typically lead to prescription of drugs

- Co-developed by more than 1 organization

- Developed by an ad hoc guideline committee rather than a standing organization

- Superceded by a drug management guideline (if a screening guideline)

- Superceded by a more recent eligible guideline

One investigator (K.E.) reviewed all CPG titles and excluded clearly ineligible guidelines. Two reviewers (K.E., K.A.T.) independently reviewed all remaining CPGs and coded them as follows: eligible - drug management, eligible - screening, eligible screening and drug management, or ineligible. For each CPGproducing organization, the most recent drug management CPG was prioritized; if none was identified, an eligible screening CPG was included. Discrepancies were resolved through consensus, with involvement of a third investigator (B.D.T.) as necessary. We uploaded the included CPGs into DistillerSR software (Evidence Partners) for data extraction.

Three physician investigators (J.L., A.M., S.S.) determined which CPGs involved first-line drug treatments on the basis of descriptions of recommended usage in each CPG. Any stand-alone set of recommendations with a statement disclosing conflicts of interest was treated as a CPG. Thus, a publication with more than 1 chapter could have had multiple CPGs, if separate chapters represented separate sets of recommendations. Because our study focused on organizational financial conflicts of interest, we selected a single eligible CPG per CPG-producing organization and considered only CPGs with a single organizational producer.

\section{Data extraction}

All data were extracted independently by 2 investigators, with the exception of determining CPG-relevant drugs, which was conducted by 1 investigator (K.E.) with validation by a second (K.A.T.). Discrepancies were resolved via consensus, with involvement of a third investigator (B.D.T.) as necessary.

We examined the included CPGs for statements on CPG funding and producers' financial conflicts of interest. For CPGs without a statement disclosing the producers' financial conflicts of interest, we searched each producer's website for information on industry sponsorship, including sponsorship of the organization's annual meeting or conference. For CPG producers with identified industry funding, we determined whether the industry funders manufactured a drug specifically recommended in the CPG or used in 
Canada as a first-line treatment for the guideline's target condition. To accomplish this, we searched industry funder websites and the Health Canada Notice of Compliance database..$^{40}$ For each included CPG, we extracted disclosures of financial conflicts of interest by all individuals listed as CPG authors or named as committee members, including the committee chair and vice-chair, if available. We also searched each CPG for text, a reference or a web link to any statement on the management of committee members' and organizational financial conflicts of interest.

\section{Data synthesis}

We categorized each CPG producer as a government-sponsored guideline organization, a disease or condition interest group, or a medical professional society. We described the proportions of CPGs in each category that disclosed organizational financial conflicts of interest in the CPGs and on producers' websites, including financial conflicts related to CPG-relevant drugs and disclosed financial conflicts of CPG committee members, as well as any steps for managing organizational financial conflicts of interest that were described in the CPGs or on the organizations' websites.

\section{Ethics approval}

This study involved only the analysis of publicly available guidelines and CPG producers' websites. As such, ethics approval was not required.

\section{Results}

Figure 1 provides details on the search for and inclusion of CPGs. We reviewed 840 CPGs at the title and abstract level, of which 635 were excluded. A total of $121 \mathrm{CPG}$ were eligible, consisting of $12(10 \%)$ developed by government-sponsored organizations, $52(43 \%)$ by disease or condition interest groups and $57(47 \%)$ by

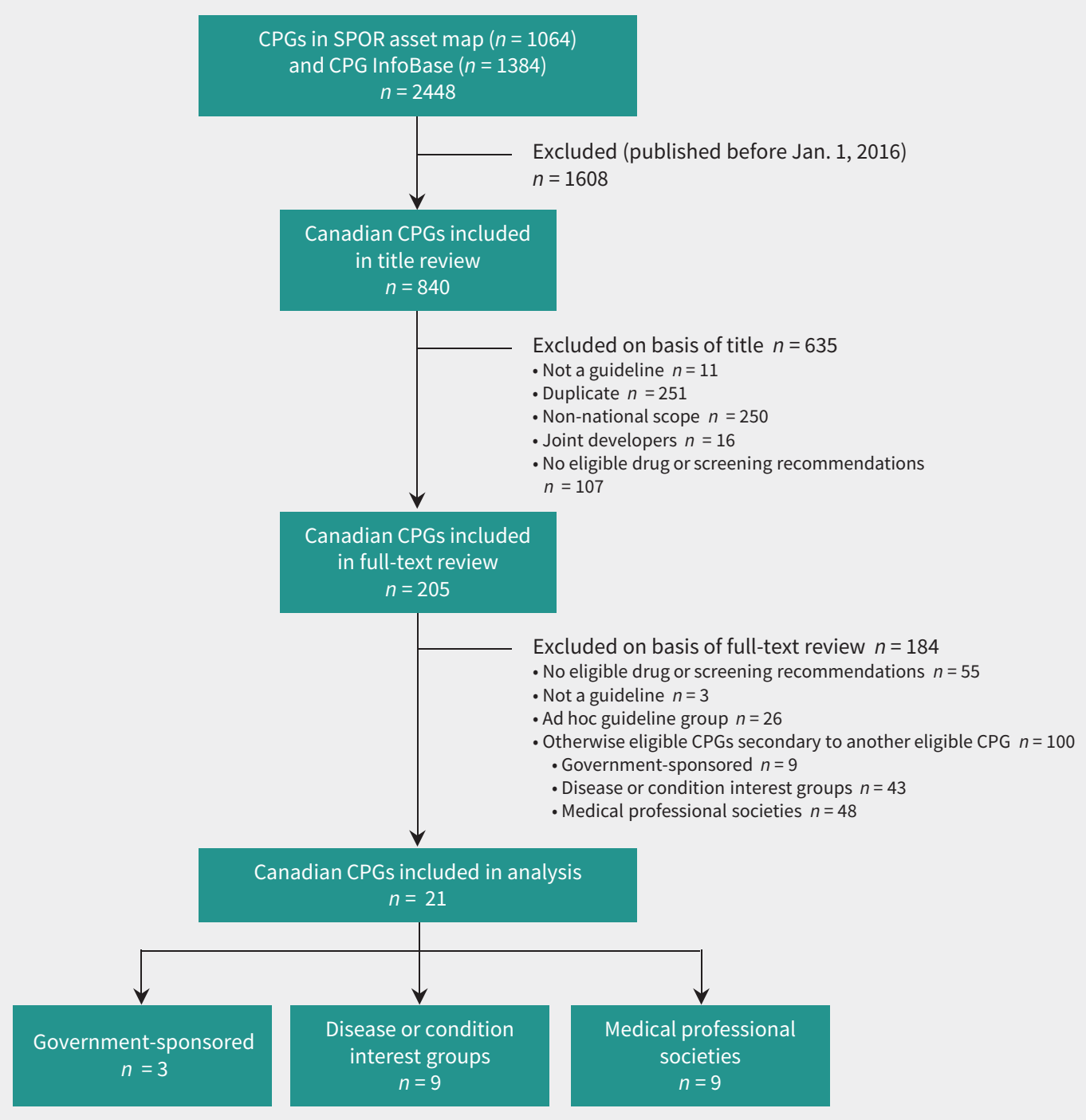

Figure 1: Inclusion of clinical practice guidelines (CPGs) found in the asset map of the Strategy for Patient-Oriented Research (SPOR) Evidence Alliance ${ }^{38}$ and the CPG Infobase. ${ }^{39}$ The initial search was conducted on Nov. 30, 2018, with a further prepublication search on Feb. 9, 2020, to ensure that no eligible CPGs from the study period were missed that might subsequently have been added to the CPG Infobase. 


\section{Guideline producer}

Year

Guideline type

Population

Scope

\section{Government-sponsored guideline organizations $(n=3)$}

Canadian Task Force on Preventive Health Care $^{41}$

Committee to Advise on Tropical Medicine and Travel ${ }^{42}$

National Advisory Committee on Immunization, Public Health Agency of Canada ${ }^{4}$

\section{Disease or condition interest groups $(n=9)$}

Canadian ADHD Resource Alliance ${ }^{44}$

Canadian HIV Trials Network ${ }^{45}$

Canadian Network for Mood and Anxiety Treatments ${ }^{46}$

Canadian Research Initiative in Substance Misuse $^{47}$

Diabetes Canada ${ }^{48}$

Heart and Stroke Foundation of Canada ${ }^{49}$

Hypertension Canada ${ }^{50}$

Kidney Cancer Research Network of Canada ${ }^{51}$

Thrombosis Canada ${ }^{52}$

\section{Medical professional societies $(n=9)$}

Association of Medical Microbiology and Infectious Disease Canada ${ }^{53}$

Canadian Academy of Child and Adolescent Psychiatry $^{54}$

Canadian Association for the Study of the Liver $^{55}$

Canadian Cardiovascular Society ${ }^{56}$

Canadian Ophthalmological Society ${ }^{57}$

Canadian Paediatric Society ${ }^{58}$

Canadian Rheumatology Association ${ }^{59}$

Canadian Urological Association ${ }^{60}$

Society of Obstetricians and Gynaecologists of Canada ${ }^{61}$
2018

2016

Screening

Screening and drug management

2018

Drug management

2018

Screening and drug management

Drug management

2018

2018

Screening and drug management drug management

Drug management

2016

2016

2017

2018

2018

2016

2018
Drug management

Drug management

Screening and drug management

Drug management

Screening and drug management

Drug management

Screening and drug management

Drug management

Screening and drug management
Pregnant women not at increased risk for asymptomatic bacteriuria

Individuals with or at risk of disseminated strongyloidiasis

Adults and children

Patients with ADHD

Adults who are at risk of acquiring HIV infection through sexual activity or injection drug use

Adults with unipolar major depressive disorder

Adults with opioid use disorders

Patients with diabetes

Children and adults with transient ischemic attack or ischemic stroke who are not candidates for immediate hyperacute thrombolysis treatment with intravenous alteplase or endovascular thrombectomy

Pregnant women with hypertension

Patients with advanced kidney cancer

Patients with deep vein thrombosis

HIV-1 infected adults

Children and adolescents with depression and/or anxiety disorders

Adults with chronic HCV infection

Patients with atrial fibrillation

Children and adults with type 1 or type 2 diabetes, of all ethnic origins

Children and adolescents

Children and adults with systemic lupus erythematosus

Patients with kidney stones

Pregnant women
Screening for asymptomatic bacteriuria in pregnancy

Prevention, assessment and management of disseminated strongyloidiasis

Influenza vaccination

Diagnosis and management of ADHD

HIV pre-exposure prophylaxis and non-occupational postexposure prophylaxis

Management of major depressive disorder (pharmacologic treatments)

Management of opioid use disorders

Prevention and management of cardiovascular disease

Prevention of ischemic stroke recurrence through identification and management of modifiable vascular risk factors

Management of hypertension in pregnancy

Management of advanced kidney cancer

Treatment of deep vein thrombosis

Early antiretroviral therapy for HIV-1

Use of SSRIs and SNRIs to manage depression and anxiety

Management of chronic hepatitis $\mathrm{C}$

Management of atrial fibrillation

Screening, diagnosis and management of diabetic retinopathy

Human papillomavirus vaccination

Assessment and monitoring of systemic lupus erythematosus

Evaluation and medical management of kidney stones

Prevention, screening and treatment of toxoplasmosis in pregnancy 
medical professional societies. Of these, 100 were excluded because they were secondary to another eligible CPG from the same organization (see Appendix 1, available at www.cmaj.ca/ lookup/suppl/doi:10.1503/cmaj.191737/-/DC1).

Of the 21 CPGs included in our analysis (Table 1), ${ }^{41-61} 12(57 \%)$ made drug management recommendations, ${ }^{43,45-48,50,52-54,56,58,60}$ $1(5 \%)$ made a screening recommendation, ${ }^{41}$ and 8 (38\%) made both drug management and screening recommendations. $^{42,44,49,51,55,57,59,61}$ In terms of the producers, 3 (14\%) of the CPGs were produced by government-sponsored organizations, ${ }^{41-43}$ $9(43 \%)$ by disease or condition interest groups, ${ }^{44-52}$ and $9(43 \%)$ by medical professional societies. ${ }^{53-61}$

\section{Disclosure of CPG producers' financial conflicts and funding}

\section{Disclosures on producers' websites}

According to information on organizations' websites (summarized in Table 2 and detailed in Appendix 2, available at www. cmaj.ca/lookup/suppl/doi:10.1503/cmaj.191737/-/DC1), 14 CPG producers $(67 \%)$ disclosed industry funding of activities, ${ }^{44,45,48-50,52,53,55-61} 4$ (19\%) disclosed only non-industry funding, ${ }^{41-43,47}$ and 3 (14\%) did not report funding. ${ }^{46,51,54}$ All 14 (100\%) of those that disclosed industry funding $44,45,48-50,52,53,55-61$ received funding from at least 1 industry partner that produced a drug recommended in the CPG, either a specific drug or a drug in a recommended class (see Appendices 3 and 4, available at www. cmaj.ca/lookup/suppl/doi:10.1503/cmaj.191737/-/DC1). Industry funding was reported on organizational websites by $0(0 \%)$ of the 3 government-sponsored organizations, ${ }^{41-43} 6(86 \%)$ of the 7 disease or condition interest groups that reported ${ }^{44,45,47-50,52}$ (2 did not report $\left.{ }^{46,51}\right)$, and all $8(100 \%)$ of the medical professional societies that reported ${ }^{53,55-61}$ ( 1 did not report ${ }^{54}$ ).

\section{Disclosures in CPGs}

All $3(100 \%)^{41-43}$ of the CPGs produced by governmentsponsored organizations reported only government funding for the CPG. Among the 18 CPGs produced by disease or condition interest groups and medical professional societies, $1(6 \%)^{57}$ reported industry funding for the CPG, and $9(50 \%)^{48,51-56,58,60} \mathrm{did}$ not report any funding of the CPG. The remaining 8 (44\%) guidelines ${ }^{44-47,49,50,59,61}$ reported that CPG development was funded only by non-industry sources. In all 8 cases, however, the non-industry funders included the CPG producer organization itself, which did not disclose any industry sponsorship of the organization in the CPG. Of the 14 organizations that disclosed organizational industry funding on their websites, ${ }^{44,45,48-50,52,53,55-61}$ none reported it in the CPG (see Table 2 and Appendix 2).

\section{Disclosure of committee members' financial conflicts}

Table 3 summarizes committee members' financial conflicts of interest by type of CPG producer (for details, see Appendix 5, available at www.cmaj.ca/lookup/suppl/doi:10.1503/cmaj.191737/-/ DC1). Among the government-sponsored organizations, the 2 with a disclosure statement reported that no committee members had financial conflicts of interest. ${ }^{41,42}$ Among the 18 CPGs from disease or condition interest groups and medical professional societies, 14 provided disclosure statements, and $12(86 \%)^{44-51,53-57,60}$ of these reported committee members with financial conflicts (the remaining 4 did not provide disclosures ${ }^{52,58,59,61}$ ); the mean proportion of committee members with financial conflicts of interest was $56 \%$. Among the 9 CPGs that identified a chair and provided a statement disclosing conflicts of interest, ${ }^{42,44-46,49,50,55-57}$ the chair reported financial conflicts in 8 cases $(88 \%) ; 44-46,49,50,55-57$ all of these CPGs were produced by disease or condition interest groups or medical professional societies.

Table 2: Summary of reported funders of clinical practice guidelines and organizational guideline producers

\begin{tabular}{|c|c|c|c|c|c|c|c|c|c|c|c|}
\hline \multirow[b]{3}{*}{$\begin{array}{l}\text { Guideline } \\
\text { producer }\end{array}$} & \multicolumn{5}{|c|}{ Funder of guideline* } & \multicolumn{6}{|c|}{ Funder of guideline producer } \\
\hline & \multicolumn{5}{|c|}{ As reported in guideline } & \multicolumn{5}{|c|}{ As reported in guideline } & \multirow{2}{*}{$\begin{array}{l}\text { Drug industry } \\
\text { funding as } \\
\text { reported on } \\
\text { producer website }\end{array}$} \\
\hline & Producer & Government & $\begin{array}{l}\text { Non- } \\
\text { profit }\end{array}$ & $\begin{array}{c}\text { Drug } \\
\text { industry }\end{array}$ & $\begin{array}{l}\text { None } \\
\text { reported }\end{array}$ & Government & $\begin{array}{l}\text { Non- } \\
\text { profit }\end{array}$ & $\begin{array}{c}\text { Drug } \\
\text { industry }\end{array}$ & Other & $\begin{array}{l}\text { None } \\
\text { reported }\end{array}$ & \\
\hline $\begin{array}{l}\text { Government- } \\
\text { sponsored } \\
\text { organizations } \\
(n=3)\end{array}$ & - & 3 & - & - & - & 2 & - & - & - & 1 & $\begin{array}{l}\text { Yes }=0 \\
\text { No }=3 \\
\text { Not reported }=0\end{array}$ \\
\hline $\begin{array}{l}\text { Disease or } \\
\text { condition } \\
\text { interest groups } \\
(n=9)\end{array}$ & 5 & 2 & 1 & - & 3 & 1 & - & - & - & 8 & $\begin{array}{l}\text { Yes }=6 \\
\text { No }=1 \\
\text { Not reported }=2\end{array}$ \\
\hline $\begin{array}{l}\text { Medical } \\
\text { professional } \\
\text { societies } \\
(n=9)\end{array}$ & 3 & 1 & 1 & 1 & 6 & - & - & - & - & 9 & $\begin{array}{l}\text { Yes }=8 \\
\text { No }=0 \\
\text { Not reported }=1\end{array}$ \\
\hline Total & 8 & 6 & 2 & 1 & 9 & 3 & 0 & 0 & 0 & 18 & $\begin{array}{l}\text { Yes }=14 \\
\text { No }=4 \\
\text { Not reported }=3\end{array}$ \\
\hline
\end{tabular}

*Sum of values in final row of this section (26) is greater than the number of guideline producers (21) because there were multiple funding sources for some of the guidelines. 
Table 3: Summary of panelists with disclosed industry-related financial conflicts of interest, by type of guideline producer

\begin{tabular}{|c|c|c|c|c|c|}
\hline $\begin{array}{l}\text { Type of } \\
\text { guideline } \\
\text { producer }\end{array}$ & $\begin{array}{l}\text { No. of panelists, } \\
\text { mean } \pm \text { SD } \\
\text { (range) }\end{array}$ & $\begin{array}{l}\text { No. }(\%) \text { of CPGs } \\
\text { with COI statement } \\
\text { for panelists }\end{array}$ & $\begin{array}{l}\% \text { of panelists with } \\
\text { disclosure of } \\
\text { industry-related } \\
\text { FCOI,* mean } \pm \text { SD } \\
\text { (range) }\end{array}$ & $\begin{array}{c}\text { Panel chair with } \\
\text { industry-related FCOI }\end{array}$ & $\begin{array}{l}\text { Panel vice-chair with } \\
\text { industry-related FCOI }\end{array}$ \\
\hline $\begin{array}{l}\text { Government- } \\
\text { sponsored } \\
\text { organizations } \\
(n=3)\end{array}$ & $\begin{array}{c}11 \pm 8.5 \\
(4-23)\end{array}$ & $\begin{array}{l}2(67) \\
0 \text { (0\%) of } 2 \text { CPGs } \\
\text { having panelists } \\
\text { with FCOI }\end{array}$ & 0 & $\begin{array}{l}\text { Chair not identified, } n=1(33 \%) \\
\text { COI statement not available, } n=1(33 \%) \\
\text { FCOI disclosed, } n=0(0 \%) \\
\text { No FCOI disclosed, } n=1(33 \%)\end{array}$ & $\begin{array}{l}\text { Vice-chair not identified, } n=2(67 \%) \\
\text { COI statement not available, } n=1(33 \%) \\
\text { FCOI disclosed, } n=0(0 \%) \\
\text { No FCOI disclosed, } n=0(0 \%)\end{array}$ \\
\hline $\begin{array}{l}\text { Medical } \\
\text { professional } \\
\text { societies } \\
(n=9)\end{array}$ & $\begin{array}{c}13.1 \pm 10.3 \\
(3-37)\end{array}$ & $\begin{array}{c}6(67) \\
4(67 \%) \text { of } 6 \text { CPGs } \\
\text { having panelists } \\
\text { with FCOI }\end{array}$ & $\begin{array}{l}53 \pm 45 \\
(0-100)\end{array}$ & $\begin{array}{l}\text { Chair not identified, } n=4(44 \%) \\
\text { COI statement not available, } n=2(22 \%) \\
\text { FCOI disclosed, } n=3(33 \%) \\
\text { No FCOI disclosed, } n=0(0 \%)\end{array}$ & $\begin{array}{l}\text { Vice-chair not identified, } n=7(78 \%) \\
\text { COI statement not available, } n=0(0 \%) \\
\text { FCOI disclosed, } n=2(22 \%) \\
\text { No FCOI disclosed, } n=0(0 \%)\end{array}$ \\
\hline
\end{tabular}

Policies or procedures for managing financial conflicts Information on policies or procedures to manage financial conflicts of interest are presented in Appendix 6 (available at www. cmaj.ca/lookup/suppl/doi:10.1503/cmaj.191737/-/DC1). Only 2 CPG producers, ${ }^{41,43}$ both government-sponsored organizations, referred to an organizational policy on management of financial conflicts of interest in CPGs, although 1 policy could not be located. ${ }^{43}$ Overall, $16(76 \%)^{41,42,44-51,53-57,60}$ of the 21 CPGs published committee members' disclosures of financial conflicts, and 5 $(24 \%)^{41,45,47,49,55}$ of these described at least 1 step related to management of committee members' conflicts of interest. Of the 14 CPGs that reported industry funding of the producer on organizational websites, ${ }^{44,45,48-50,52,53,55-61} 3(21 \%)^{44,49,50}$ stated in the CPG that industry partners were not permitted to fund guideline development. The lone CPG that reported industry funding for its development stated that industry partners did not participate in committee member selection and did not review the recommendations before publication. ${ }^{57}$ None of the 14 producers with industry funding mentioned the existence of a committee or process to manage organizational financial conflicts of interest and their possible influence on the CPG.

\section{Interpretation}

All 3 of the CPGs from government-sponsored organizations that we examined reported no industry funding, whereas 14 (93\%) of 15 disease or condition interest groups and medical specialty societies that disclosed funding sources on their websites reported industry funding ( 3 did not report). No organization with industry funding disclosed organizational financial conflicts of interest in a CPG or described any mechanism to review or mitigate the influence of organizational financial conflicts of interest. In CPGs for which the producers received industry funding and provided individual disclosure statements, the mean proportion of CPG committee members with disclosed financial conflicts of interest was 56\%, including all 8 chairs from these organizations with CPGs for which a chair could be identified.

The only previous study that addressed disclosure of financial conflicts of interest by CPG-producing organizations found that just 4 (1\%) of 290 international CPGs (from 95 organizations) that were published in 2012 provided a financial disclosure statement for the producer organization within the CPG. ${ }^{2}$ Shnier and colleagues ${ }^{35}$ examined committee members' disclosures of financial conflicts of interest for 28 Canadian CPGs with first-line drug recommendations that were published in 2012 and 2013, and found that just under $50 \%$ of committee member disclosures included industry financial conflicts of interest. Our findings suggest that little has changed in Canadian CPGs in recent years, despite guidance from GIN and the Institute of Medicine (now the National Academy of Medicine) aimed at reducing the presence and influence of financial conflicts of interest in CPGs. 22,23

The GIN principles for managing conflicts of interest in guidelines include statements that guideline developers should "make all possible efforts" to not include committee members with direct financial conflicts of interest and that no member of a guideline development group with direct financial conflicts of interest should be involved in deciding the direction or strength of a recommendation. ${ }^{22}$ The Institute of Medicine has similarly recommended that "whenever possible" CPG committee members should not have conflicts of interest, that members with conflicts of interest should be in the minority, and that chairs and cochairs should be persons without any conflicts of interest. ${ }^{23}$ According to the findings of our study, these recommendations have been largely ignored by many Canadian disease or condition interest groups and medical professional societies that produce CPGs.

Neither the Institute of Medicine recommendations nor the GIN principles directly address the relationship between CPG producers and industry funders or the disclosure of such 
relationships in CPGs. The results of our study show that failure to disclose CPG producers' financial conflicts of interest continues to be widespread. Canadian CPG producers routinely receive funding from industry sources, including from companies that produce drugs directly relevant to the guideline recommendations, but this funding is not disclosed within the CPGs. Some, but not all, CPGs from these producers included disclosures of committee members' financial conflicts of interest. However, we did not find any examples among CPG producers with organizational financial conflicts of interest in which any CPG committee members were restricted in their participation because of their financial conflicts.

Ioannidis ${ }^{7}$ recently suggested that specialty societies could abstain from having their members write their own guidelines by instead forming CPG committees of methodologists and people with clinical expertise outside of the CPG subject matter. Content experts from the societies, who may have financial conflicts of interest, could comment and share expertise but would not make decisions on recommendations. ${ }^{7}$ Industry partnerships with disease or condition interest groups and medical professional societies are often lucrative. As highlighted by Ioannidis, ${ }^{7}$ the American Heart Association receives almost US\$200 million annually in corporate support, and almost $80 \%$ of the annual budget of the European Society of Cardiology comes from industry. Our results suggest that disease or condition interest groups and medical professional societies have not taken steps to ensure that their CPGs are independent from industry funder influences.

Organizations that depend on industry funding and engage in guideline development should disclose their financial conflicts of interest and should commission independent panels to manage financial conflicts of interest, including organizational conflicts related to industry funding. This could be done by contracting with an independent body, such as a university ethics centre, to oversee implementation of a plan to manage organizational financial conflicts of interest. These activities would include monitoring interactions between the organization and its CPG committees to reduce the risk of industry influence. Organizations should also establish policies, consistent with GIN principles, ${ }^{22}$ to prohibit individuals with financial conflicts of interest from having input to or voting on recommendations. The independent oversight body could vet appointments to CPG committees and ensure compliance with GIN principles.

Reform is urgently needed. Ideally, such reform would come from the CPG-producing organizations themselves, either out of a desire to better serve the public and society or through pressure from members. When CPG producers are funded by industry, full disclosure and independent oversight are needed. If governments and other organizations without industry funding produced more CPGs, our dependence on CPGs produced by organizations with funding from industry would be decreased. Additionally, journals that publish guidelines should consider the degree to which CPG producers, in addition to committee members, have financial conflicts of interest and whether they are managed appropriately. Additional studies should examine the reporting of organizational financial conflicts of interest in
CPGs from other countries and should re-examine reporting in Canadian CPGs in 5 to 10 years, to assess changes.

\section{Limitations}

We reviewed only 1 CPG per CPG producer. The CPG producers may have reported organizational financial conflicts of interest differently in other CPGs that were not reviewed, although we consider this unlikely. We searched 2 databases for CPGs, and it is possible that they did not capture all relevant CPGs. Because of resource considerations, a single reviewer reviewed CPG titles to remove clearly ineligible citations, and a single reviewer conducted internet searches to ascertain CPG-relevant drugs. We examined only organizational and committee members' financial conflicts of interest that were disclosed, and the extent of financial conflicts for both CPG producers and committee members is likely underestimated. We did not attempt to determine whether financial conflicts of interest were associated with the degree to which recommendations on drug management were consistent with the best available evidence. We did not track discrepancies in data extraction in a way that allowed quantification, but there were no major discrepancies in extraction for any CPGs.

\section{Conclusion}

Most Canadian national CPGs on the use of drugs are produced by disease or condition interest groups and medical professional societies that receive funding from pharmaceutical companies with a direct interest in the drugs under consideration. We did not find any examples where these organizational relationships were disclosed in a CPG. A high proportion of committee members who develop CPGs produced by disease or condition interest groups and medical professional societies also have industry-related financial conflicts of interest. We did not find any examples where these organizations stated that they restricted committee membership or participation on the basis of industry-related financial conflicts of interest. Furthermore, we did not find any examples of disease or condition interest groups or medical professional societies with policies on the management of organizational financial conflicts of interest.

\section{References}

1. Moynihan R, Bero L, Hill S, et al. Pathways to independence: towards producing and using trustworthy evidence. BMJ 2019;367:16576.

2. Campsall P, Colizza K, Straus S, et al. Financial relationships between organizations that produce clinical practice guidelines and the biomedical industry: a cross-sectional study. PLoS Med 2016;13:e1002029.

3. Bindslev JB, Schroll J, Gøtzsche PC, et al. Underreporting of conflicts of interest in clinical practice guidelines: cross sectional study. BMC Med Ethics 2013;14:19.

4. Tricoci P, Allen JM, Kramer JM, et al. Scientific evidence underlying the ACC/ AHA clinical practice guidelines. JAMA 2009;301:831-41.

5. Fanaroff AC, Califf RM, Windecker S, et al. Levels of evidence supporting American College of Cardiology/American Heart Association and European Society of Cardiology guidelines, 2008-2018. JAMA 2019;321:1069-80.

6. Boyd EA, Akl EA, Baumann M, et al.; ATS/ERS Ad Hoc Committee on Integrating and Coordinating Efforts in COPD Guideline Development. Guideline funding and conflicts of interest: article 4 in integrating and coordinating efforts in COPD guideline development. An official ATS/ERS workshop report. Proc Am Thorac Soc 2012;9:234-42. 
7. Ioannidis JPA. Professional societies should abstain from authorship of guidelines and disease definition statements. Circ Cardiovasc Qual Outcomes 2018;11:e004889.

8. Ioannidis JPA, Thombs BD. A user's guide to inflated and manipulated impact factors. Eur J Clin Invest 2019;49:e13151.

9. Lundh A, Lexchin J, Mintzes B, et al. Industry sponsorship and research outcome. Cochrane Database Syst Rev 2017;2:MR000033.

10. Ahn R, Woodbridge A, Abraham A, et al. Financial ties of principal investigators and randomized controlled trial outcomes: cross-sectional study. BMJ 2017;356:i6770.

11. Barnes DE, Bero LA. Why review articles on the health effects of passive smoking reach different conclusions. JAMA 1998;279:1566-70.

12. Dunn AG, Arachi D, Hudgins J, et al. Financial conflicts of interest and conclusions about neuraminidase inhibitors for influenza: an analysis of systematic reviews. Ann Intern Med 2014;161:513-8.

13. Lesser LI, Ebbeling CB, Goozner M, et al. Relationship between funding source and conclusion among nutrition-related scientific articles. PLoS Med 2007;4:e5.

14. Jørgensen AW, Hilden J, Gøtzsche PC. Cochrane reviews compared with industry supported meta-analyses and other meta-analyses of the same drugs: systematic review. BMJ 2006;333:782.

15. Mandrioli D, Kearns CE, Bero LA. Relationship between research outcomes and risk of bias, study sponsorship, and author financial conflicts of interest in reviews of the effects of artificially sweetened beverages on weight outcomes: a systematic review of reviews [published erratum in PLOS One 2020; 15:e230469]. PLoS One 2016;11:e0162198.

16. Wang AT, McCoy CP, Murad MH, et al. Association between industry affiliation and position on cardiovascular risk with rosiglitazone: cross sectional systematic review. BMJ 2010;340:c1344.

17. Ebrahim S, Bance S, Athale A, et al. Meta-analyses with industry involvement are massively published and report no caveats for antidepressants. J Clin Epidemiol 2016;70:155-63.

18. Raichand S, Dunn AG, Ong MS, et al. Conclusions in systematic reviews of mammography for breast cancer screening and associations with review design and author characteristics. Syst Rev 2017;6:105.

19. Yank V, Rennie D, Bero LA. Financial ties and concordance between results and conclusions in meta-analyses: retrospective cohort study. BMJ 2007;335: 1202-5.

20. Spurling GK, Mansfield PR, Montgomery BD, et al. Information from pharmaceutical companies and the quality, quantity, and cost of physicians' prescribing: a systematic review. PLoS Med 2010; 7:e1000352

21. Fickweiler F, Fickweiler W, Urbach E. Interactions between physicians and the pharmaceutical industry generally and sales representatives specifically and their association with physicians' attitudes and prescribing habits: a systematic review. BMJ Open 2017;7:e016408.

22. Schünemann HJ, Al-Ansary LA, Forland F, et al.; Board of Trustees of the Guidelines International Network. Guidelines International Network: principles for disclosure of interests and management of conflicts in guidelines. Ann Intern Med 2015;163:548-53.

23. Institute of Medicine (US), Committee on Standards for Developing Trustworthy Clinical Practice Guidelines; Graham R, Mancher M, Miller Wolman, et al., editors. Clinical practice guidelines we can trust. Washington: National Academies Press (US); 2011.

24. Developing NICE guidelines: the manual. London (UK): National Institute for Health and Care Excellence; 2014

25. Djulbegovic B, Guyatt $\mathrm{G}$. Evidence vs consensus in clinical practice guidelines. JAMA 2019;322:725-6.

26. Cosgrove L, Bursztajn HJ, Erlich D, et al. Conflicts of interest and the quality of recommendations in clinical guidelines. J Eval Clin Pract 2013;19:674-81.

27. Norris SL, Holmer HK, Ogden LA, et al. Conflict of interest in clinical practice guideline development: a systematic review. PLoS One 2011;6:e25153.

28. Tibau A, Bedard PL, Srikanthan A, et al. Author financial conflicts of interest, industry funding, and clinical practice guidelines for anticancer drugs. J Clin Oncol 2015;33:100-6.

29. Norris SL, Holmer HK, Ogden LA, et al. Conflict of interest disclosures for clinical practice guidelines in the National Guideline Clearinghouse [published erratum in PLoS One 2013;8]. PLoS One 2012;7:e47343.
30. Choudhry NK, Stelfox HT, Detsky AS. Relationships between authors of clinical practice guidelines and the pharmaceutical industry. JAMA 2002;287:612-7.

31. Norris SL, Burda BU, Holmer HK, et al. Author's specialty and conflicts of inter est contribute to conflicting guidelines for screening mammography. J Clin Epidemiol 2012;65:725-33.

32. Cosgrove L, Shaughnessy AF, Peters SM, et al. Conflicts of interest and the presence of methodologists on guideline development panels: a crosssectional study of clinical practice guidelines for major depressive disorder. Psychother Psychosom 2017;86:168-70.

33. Shaneyfelt TM, Centor RM. Reassessment of clinical practice guidelines: go gently into that good night. JAMA 2009;301:868-9.

34. Sox HC. Conflict of interest in practice guidelines panels. JAMA 2017;317:1739-40.

35. Shnier A, Lexchin J, Romero M, et al. Reporting of financial conflicts of interest in clinical practice guidelines: a case study analysis of guidelines from the Canadian Medical Association Infobase. BMC Health Serv Res 2016;16:383.

36. Institute of Medicine (US), Committee to Advise the Public Health Service on Clinical Practice Guidelines; Field MJ, Lohr KN, editors. Clinical practice guidelines: directions for a new program. Washington: National Academies Press (US); 1990.

37. Institute of Medicine (US), Committee on Conflict of Interest in Medical Research, Education, and Practice; Lo B, Field MJ, editors. Conflict of interest in medical research, education, and practice. Washington: National Academies Press (US); 2009

38. Asset map of Canadian clinical practice guidelines developers. Toronto: SPOR Evidence Alliance. Available: https://sporevidencealliance.ca/cpg-asset-map/ (accessed 2020 May 20).

39. CPG infobase: clinical practice quidelines [database]. Ottawa: Joule Inc. Available: https://joulecma.ca/cpg/homepage (accessed 2020 Mar. 1).

40. Notice of compliance (NOC) database [database]. Ottawa: Health Canada; 2017 Oct. 5. Available: www.canada.ca/en/health-canada/services/drugs-health-products/ drug-products/notice-compliance/database.html (accessed 2020 Mar. 1)

41. Moore A, Doull M, Grad R, et al.; Canadian Task Force on Preventive Health Care. Recommendations on screening for asymptomatic bacteriuria in pregnancy. CMAJ 2018;190:E823-30.

42. Boggild AK, Libman M, Greenaway C, et al.; Committee to Advise on Tropical Medicine and Travel (CATMAT). CATMAT statement on disseminated strongyloidiasis: prevention, assessment and management guidelines. Can Commun Dis Rep 2016;42:12-9.

43. An Advisory Committee Statement (ACS) National Advisory Committee on Immunization (NACl): Canadian immunization guide chapter on influenza and statement on seasonal influenza vaccine for 2018-2019. Ottawa: Public Health Agency of Canada; 2018.

44. Canadian ADHD practice guidelines. 4th ed. Toronto: Canadian ADHD Resource Alliance; 2018

45. Tan DHS, Hull MW, Yoong D, et al.; Biomedical HIV Prevention Working Group of the CIHR Canadian HIV Trials Network. Canadian guideline on HIV preexposure prophylaxis and nonoccupational postexposure prophylaxis [published erratum in CMAJ 2018;190:E782]. CMAJ 2017;189:E1448-58.

46. Kennedy SH, Lam RW, McIntyre RS, et al.; CANMAT Depression Work Group Canadian Network for Mood and Anxiety Treatments (CANMAT) 2016 clinical guidelines for the management of adults with depressive disorder: Section 3. Pharmacological treatments. Can J Psychiatry 2016;61:540-60.

47. Bruneau J, Ahamad K, Goyer MÈ, et al.; CIHR Canadian Research Initiative in Substance Misuse. Management of opioid use disorders: a national clinical practice guideline. CMAJ 2018;190:E247-57.

48. Diabetes Canada Clinical Practice Guidelines Expert Committee; Stone JA Houlden RL, Lin P, et al. Cardiovascular protection in people with diabetes [published erratum in Can J Diabetes 2019;43:154]. Can J Diabetes 2018; 42(Suppl 1):S162-9.

49. Wein T, Lindsay MP, Côté R, et al.; Heart and Stroke Foundation Canadian Stroke Best Practice Committees. Canadian stroke best practice recommendations: secondary prevention of stroke, sixth edition practice guidelines, update 2017. Int J Stroke 2018;13:420-43.

50. Butalia S, Audibert F, Côté AM, et al. Hypertension Canada's 2018 guidelines for the management of hypertension in pregnancy. Can J Cardiol 2018; 34:526-31. 
51. Reaume MN, Basappa NS, Wood L, et al. Management of advanced kidney cancer: Canadian Kidney Cancer Forum (CKCF) consensus update 2017. Can Urol Assoc J 2017;11:310-20.

52. Deep vein thrombosis (DVT): treatment. Thrombosis Canada; 2016. Available: http://thrombosiscanada.ca/wp-content/uploads/2016/05/3_Deep-Vein -Thrombosis-Treatment-2016May19-FINAL.pdf (accessed 2020 Mar. 1).

53. Becker M, Cox J, Evans GA, et al. AMMI Canada position statement: the use of early antiretroviral therapy in HIV-infected persons. JAMMI 2016;1. doi: 10.3138/jammi.1.2.01.

54. Garland EJ, Kutcher S, Virani A, et al. Update on the use of SSRIs and SNRIs with children and adolescents in clinical practice. J Can Acad Child Adolesc Psychiatry 2016;25:4-10.

55. Shah H, Bilodeau M, Burak KW, et al.; Canadian Association for the Study of the Liver. The management of chronic hepatitis C: 2018 guideline update from the Canadian Association for the Study of the Liver. CMAJ 2018;190: E677-87.
56. Andrade JG, Verma A, Mitchell LB, et al.; CCS Atrial Fibrillation Guidelines Committee. 2018 focused update of the Canadian Cardiovascular Society guidelines for the management of atrial fibrillation. Can J Cardiol 2018;34:1371-92.

57. Hooper P, Boucher MC, Cruess A, et al. Excerpt from the Canadian Ophthalmological Society evidence-based clinical practice guidelines for the management of diabetic retinopathy. Can J Ophthalmol 2017;52(Suppl 1):S45-74.

58. Salvadori MI. Human papillomavirus vaccine for children and adolescents. Paediatr Child Health 2018:23:262-5.

59. Keeling SO, Alabdurubalnabi Z, Avina-Zubieta A, et al. Canadian Rheumatology Association recommendations for the assessment and monitoring of systemic lupus erythematosus. J Rheumatol 2018;45:1426-39.

60. Dion M, Ankawi G, Chew B, et al. CUA guideline on the evaluation and medical management of the kidney stone patient - 2016 update. Can Urol Assoc J 2016;10:E347-58.

61. Paquet C, Yudin MH. No. 285 - Toxoplasmosis in pregnancy: prevention, screening, and treatment. J Obstet Gynaecol Can 2018;40:e687-93.
Competing interests: Katharine Elder formerly worked as the administrator of the Canadian Task Force on Preventive Health Care (CTFPHC), which was the producer of one guideline included in the present study (cited as reference 41). Brett Thombs, Ainsley Moore and Sharon Straus are the chair, vice-chair and director of knowledge translation, respectively, for the CTFPHC. The present work was not commissioned or funded by the CTFPHC, and the authors participated in the study outside of their responsibilities with the CTFPHC. No other competing interests were declared.

This article has been peer reviewed.

Affiliations: Lady Davis Institute for Medical Research (Elder, Turner, Thombs), Jewish General Hospital and McGill University, Montréal, Que.; Department of Counselling and School of Psychology (Cosgrove), University of Massachu- setts, Boston, Mass.; School of Health Policy and Management (Lexchin, Shnier), York University, Toronto, Ont.; Department of Family Medicine (Moore), McMaster University, Hamilton, Ont.; Knowledge Translation Program (Straus), Li Ka Shing Knowledge Institute, St. Michael's Hospital, Toronto, Ont.

Contributors: All of the authors were responsible for study conception and design and for protocol development. Katharine Elder, Kimberly Turner and Brett Thombs were responsible for title and full-text review of guidelines included in the study and for subsequent data extraction. Katharine Elder and Brett Thombs analyzed and interpreted the results. Katharine Elder and Brett Thombs drafted the manuscript. All of the authors provided critical review of the manuscript, provided final approval of the version to be published and agreed to be accountable for all aspects of the work.

Funding: Kimberly Turner was supported by a Fonds de recherche du Québec - Santé (FRQS) masters training award; Brett Thombs was supported by an FRQS researcher award; and Sharon Straus was funded by a Tier 1 Canada Research Chair in Knowledge Translation and Quality of Care, the Squires Chalmers Chair in Medicine and the Trimmer Chair in Geriatric Medicine, all outside of the submitted work.

Data sharing: All data that were extracted and analyzed for this study are available in the text, tables and figures, or appendices.

Accepted: Mar. 18, 2020

Correspondence to: Brett Thombs, brett. thombs@mcgill.ca 